\title{
Remembering Dennis Ahnen
}

\author{
Robert S. Bresalier ${ }^{1}$
}

Accepted: 9 October 2021 / Published online: 21 October 2021

(C) The Author(s), under exclusive licence to Springer Science+Business Media, LLC, part of Springer Nature 2021

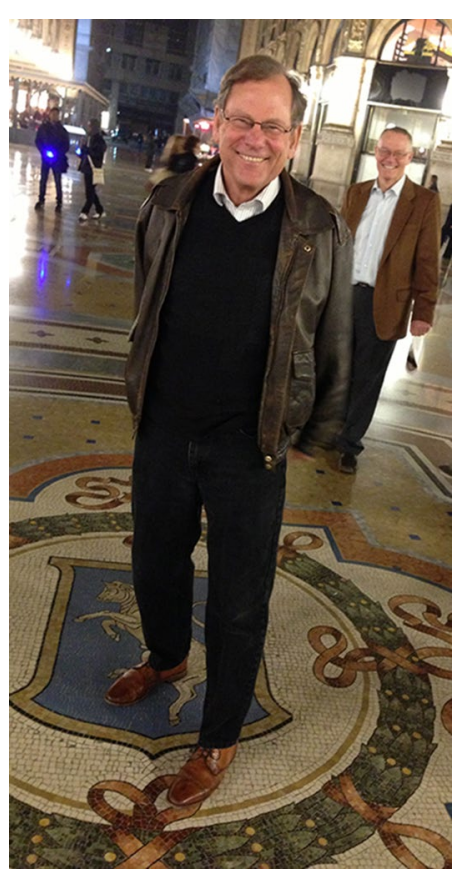

It has been a little over a year (August 2020) since our colleague and my friend Dennis Ahnen passed away after a brave battle with appendiceal cancer. Dennis was a long-time supporter and prolific reviewer for Digestive Diseases and Sciences. We edited a Special Issue in 2015 entitled "Colorectal Cancer Screening Past Present and Future" which still stands as a timely and comprehensive summary of this important area. I was honored that Dennis asked me to assist him with this project and was and remain rather proud of the result.

I was first introduced to Dennis in the early 1980s by my UCSF colleague Rick Boland as I became interested in the biology and prevention of colorectal cancer, working with him closely on several projects until Dennis' passing. He was always generous in his support and tireless in his enthusiasm. Dennis was a true pioneer in translational research, realizing early in his career the potential and importance of translating laboratory findings into clinical practice. We worked together for over 2 decades as part of John Baron's Polyp Prevention Study Group, publishing several seminal studies emphasizing

Robert S. Bresalier

rbresali@mdanderson.org

1 Department of Gastroenterology, Hepatology and Nutrition, University of Texas MD Anderson Cancer Center, Houston, TX, USA the potential of colorectal cancer chemoprevention. His contributions and commitment to gastroenterology and cancer prevention were recognized through many awards and accolades including the AGAs William Beaumont Prize and Lifetime Achievement awards from the Collaborative Group of the Americas on Inherited Gastrointestinal Cancers and the National Colorectal Cancer Roundtable.

Dennis' many accomplishments were well summarized in accolades from the National Colorectal Cancer Roundtable and the AGA during his life and at the time of his passing and can easily be found online. Rather than repeat these in detail, I want to take this opportunity to remember him as not only as a colleague, but as my friend. There was not a single instance when Dennis did not greet me (or anyone else) with a huge smile and an outstretched hand shake. You will never find a picture of Dennis without a smile (see accompanying photograph). He was a mentor to many of us in the field of cancer prevention, and tireless in his support and enthusiasm. He loved to travel, often with his family, with sabbaticals in London, England, and Melbourne, Australia, marking his love for new venues and experiences. His passion for his work was marked by matchless enthusiasm. After a long career at the University of Colorado and the Denver VA Medical Center, Dennis continued his passion for cancer prevention research and community outreach in Boulder, Colorado and in Denver, where I often communicated with him when my son enrolled at the University of Colorado, Boulder. On one of these occasions, Dennis informed me that he had metastatic appendiceal cancer, but I could still see his "smile" despite this terminal diagnosis with which he was all too familiar, even over the telephone.

So thank you Dennis. I miss you, my friend.

Bob Bresalier

Special Issue/Associate Editor

Digestive Diseases and Sciences

Publisher's Note Springer Nature remains neutral with regard to jurisdictional claims in published maps and institutional affiliations. 